\title{
HROTSVITA DE GANDERSHEIM: DULCITIUS, EJEMPLO DE TRADICIÓN HAGIOGRÁFICA Y ARGUMENTATIVA
}

\author{
Hrotswitha of Gandersheim: Dulcitius, an Example of Argumentative and \\ Hagiographic Tradition
}

Henry Campos Vargas ${ }^{1}$

A Mercedes, mi madre

\begin{abstract}
RESUMEN
El presente artículo muestra cómo las acta de los mártires y Terencio han podido influir en el drama Dulcicio de Hrosvita de Gandersheim. Se destacan los cambios e innovaciones introducidos por Hrosvita. Además, se examina su argumentación como un tipo de tradición en la literatura hagiográfica. Al final del artículo, se ofrece una traducción de este drama del latín al español.
\end{abstract}

Palabras clave: Literatura medieval, latín, latín medieval, Hrosvita de Gandersheim, acta de los mártires, Terencio, argumentación.

\begin{abstract}
This paper shows how acta of martyrs and Terence would influence in Dulcitius Drama of Hrosvita of Gandersheim. It points out changes and innovations introduce by Hrosvita. Also, argumentation is examined as a kind of tradition in hagiographic literature. At the end of the paper, there is a translation of this drama from Latin to Spanish.
\end{abstract}

Key Words: Medieval Literature; latin, Medieval Latin, Hrosvita of Gandersheim, acta of martyrs, Terence, argumentation.

\section{Introducción}

Hrotsvita de Gandersheim, quien, en el prefacio a sus dramas, se llama a sí misma Clamor Validus Gandeshemensis, la 'potente voz de Gandersheim' (Hrotswitha of Gandersheim, 2013, p. 2), —aunque en otros sitios se declara también nesciola (ignorantilla) y dotada de ingeniolum 'pequeño ingenio' (Prampolini, 1955, p. 331) - fue una monja benedictina del siglo décimo; pasó la mayor parte de su vida en la abadía imperial de Gandersheim, fundada en el 852 por la dinastía Ludolfinga, precedente directo

\footnotetext{
${ }^{1}$ Universidad de Costa Rica. Escuela de Filología, Lingüística y Literatura. Costa Rica.

Correo electrónico: hcamposv@yahoo.es
}

Recepción:15-11-2018 Aceptación: 17-08-2019 
de la dinastía Otoniana, en la Baja Sajonia, en las montañas de Harz, entre las diócesis de Hildesheim y Mainz. Esta abadía, así como otras establecidas bajo esta dinastía, se convirtieron en importantes centros de enseñanza, difusión y preservación de la civilización bajo la égida de destacadas mujeres. Para la época de Hrotsvita, “A pesar de los esfuerzos de los Otones para difundir la cultura, ésta siguió siendo privilegio de los centros episcopales y monásticos” (Prampolini, 1955, p. 322).

Lo poco que se conoce sobre la vida de Hrotsvita se ha extraído de las cartas dedicatorias y prefacios a sus composiciones: "She lived, studied, and wrote during the abbey's golden age under Gerberga II's rule, a period of peace, tranquillity, and genuine devotion to learning and service" (Hrotswitha of Gandersheim, 2000, p. 7).

Sobre su nombre puede afirmarse, junto con otros estudiosos, que ella misma lo escribía como Hrotsvit en latín. Respecto de su significado mucho se ha especulado, por ejemplo, se ha querido traducirlo como Weisse Rose 'rosa blanca', rascher Witz 'ingenio rápido', entre otros. En 1838, Jacob Grimm formuló una hipótesis revolucionaria: partiendo de la introducción a los dramas, sostuvo que su nombre sajón derivaba de hruot, y suid, por su orden clamor y validus, en latín. En efecto, en la introducción, Hrotsvita había escrito: "Unde ego, Clamor Validus Gandeshemensis non recusavi illum imitari dictando dum alii colunt legendo" (Hrotswitha of Gandersheim, 2013, p. 2).

Grimm coligió de esta cita que "as she wrote "Clamor Validus Gandeshemensis" in apposition to "ego", he observed she must have intended it either as a mere Latinization of her name or as a pun" (Hrotswitha of Gandersheim, 2000, p. 4).

Katharina Wilson, en cambio, señala:

It is not merely a Latinization of "Hrotsvit" but, more important, an interpretation of it and an explanation of her self of her earthly mission as suggested by her name. Seen as allegotization of her name, "Clamor Validus" could be best rendered as "Forceful Testimony" (that is, for God), or "Vigorous (valid) Attestation" (that is of Christian truth) (Hrotswitha of Gandersheim, 2000, p. 4).

Su formación religiosa permite comprender por qué en sus dramas la vida eremítica, junto al martirio, aparecen como las más altas manifestaciones de la fe cristiana, aunadas a la virtud de la castidad. 
Hrotsvita no solo es la primera poeta alemana (Prampolini, 1955, p. 327), sino que su obra dramática "representa la única producción del teatro europeo desde las tragedias de Séneca hasta las primeras representaciones cristianas, es decir, en el espacio de un milenio" (Prampolini, 1955, p. 331).

Actualmente, el texto más antiguo que se conserva se encuentra en el Codex Emmeram-Munich (clm 14485-1-150). Este manuscrito posiblemente fue producido en Gandersheim. Fue hallado por el humanista alemán Conrad Celtis en 1494, para quien ella fue nada menos que la Safo alemana. Pocos años después, en 1501, vio la luz su publicación, a cargo de Hieronymus Holtzel en Nuremberg.

La obra de esta autora medieval comprende ocho leyendas: Maria, Ascensio, Gangolfus, Pelagius, Basilius, Theophilius, Dionysius, Agnes; seis dramas: Gallicanus, Dulcitius, Callimachus, Paphnutius, Abraham, Sapientia, con una carta a sus protectores; un poema a San Juan y dos obras épicas: Gesta Oddonis y Primordia.

Respecto de sus obras dramáticas, que corresponden al objeto de esta investigación, estos títulos parecen haber sido producto de su abreviación para el mundo los hombres del Renacimiento, merced a Conrad Celtis, tal y como W. Berschin destaca:

Bei Hrotsvit aber latuen die Titel:

Conversio Gallicani principis militiae

Passio SS. virginum Agapis, Chioniae et Hirenae

Resuscitatio Drusianae et Calimachi

Lapsus et conversio Mariae neptis Habrahae heremicolae

Conversio Taidis meretricis

Passio SS. virginum Sifei, Spei et Karitatis (Berschin, 1985, p. 3)

Pero para Hrosvita, los títulos se leen así:

Conversiones del ejército del príncipe Galicano

Pasión de las Santas Vírgenes Ágape, Quionia e Irene

Resurrección de Drusina y Calímaco

Lapsus y conversión de María, nieta de Abraham heremícola 
Conversión de la meretriz Thais

Pasión de las Santa Vírgenes Sifei, Esperanza y Caridad (traducción del autor).

Estas obras en particular forman parte de los exempla hagiográficos propios tanto de la práctica benedictina como de la homilética de la época. En el ámbito literario, cabe destacar, que "la historiografía y la hagiografía recibieron una contribución notable de Widukind de Corvey (muerto hacia el 1004) con las Res gestae saxonicae y de Routger de Colonia con la Vita Brunonis, ambas obras compuestas alrededor del 967" (Prampolini, 1955, p. 323).

En el caso particular de esta monja benedictina, se ven enriquecidos por una elocuencia unida a la fe cristiana. Característico de su estilo, es el realismo de la ambientación, descubierto a través del recurso a personajes, contextos y espacios históricos; así como la apelación constante a lo concreto, frente a la abstracción de la fe, todo dentro de una perspectiva eminentemente moralizante.

Para Katharina Wilson:

Hrosvit's virtuosity in adorning her works with diverse rhetorical ornaments (she uses, as I have argued elsewhere, almost all of the figures and tropes discussed by Donatus, Isidore, and the Venerable Bede), as well as the etymologia, arithmetica, and musica lessons incorporated into her plays, bear eloquent testimony to her training in, and respect for, the artes (Hrotswitha of Gandersheim, 2000, p. 7).

$\mathrm{Su}$ arte dramático posiblemente estuvo fuertemente influido por la cultura bizantina. Este nexo habría tenido lugar a través de Teófano Skleraina, esposa bizantina de Otón II, quien visitó frecuentemente la abadía de Gandersheim. Sobre la existencia de incipientes piezas teatrales de orden eclesiástico en Constantinopla, se cuenta con el testimonio de Liudprand de Cremona, embajador a quien Otón I encomendó los arreglos del matrimonio de Otón II ante el emperador Nicéforas Focas.

En los dramas de Hrotsvita, predomina el elemento femenino, contrario a lo que ocurre en sus leyendas. Su prosa rítmica rimada contrasta sobremanera con los hexámetros leoninos de siete de sus leyendas y los dísticos elegíacos del Gangolfus. Esta particularidad formal parece estar asociada, de acuerdo con Larissa Bonfante, al hecho de que Hrotsvita, a 
diferencia de sus contemporáneos, descubrió que Terencio había escrito sus comedias en verso y no en simple prosa (Hrotswitha of Gandersheim, 2013, p. xix).

\section{Discurso y acción en Dulcitius}

Esta obra acusa una clara subordinación del elemento dramático al discursivo, aspecto en el que sería desaprobada por Aristóteles. W. Berschin incluso ha identificado: "zum "Dulcitius" zu 42\% (...) schon in der Vorlage in directer Rede geschrieben" (Berschin, 1985, p. 9). ${ }^{2}$

Desde la perspectiva de los grandes trágicos griegos, Esquilo, Sófocles y Eurípides, puede considerarse que el distanciamiento es máximo respecto de Esquilo, dada la proximidad de este con las funciones originarias del coro. Sófocles, en cambio, ofrece un dominio de los elementos dramáticos y un perfecto equilibrio de forma y fondo. Es Eurípides quien, debido a su empleo de la retórica en el drama, aparece más próximo.

La presencia de la retórica se evidencia a partir de la presencia de discursos propios de los géneros judicial, epidíctico y deliberativo.

El predominio de los rasgos retorizantes de la composición se aprecian en las continuas interrupciones de la acción dramática. En efecto, la acción está subordinada permanentemente a lo discursivo.

Al respecto, se pueden extender a esta obra las siguientes consideraciones sobre la obra de Sófocles:

El agón trágico, sin embargo, adquiere su forma definitiva cuando se invierten los términos y adopta como modelo los discursos enfrentados de la retórica. La libertad compositiva de los primeros agones será sustituida por una rigidez estructural particularmente patente en las tragedias de Eurípides, aunque, según Duchemin, sólo a partir de Medea (431) (...). Aún no tenemos las "marcas" euripídeas de inicio del agón, sino que nos mantenemos dentro de la fluidez dramática típicamente sofoclea; pero el llamado "discurso natural" ("natürlische Beredsamkeit"), con su sucesión de lugares comunes, sentencias, comparaciones, etc., que parecen nacer

\footnotetext{
${ }^{2}$ Traducción del original por parte del autor: "Hasta un $42 \%$ de la muestra del Dulcitius está escrito en estilo directo" (1985, p. 9).
} 
espontáneamente, es sustituido ya por dos discursos simétricamente organizados desde el punto de vista argumentativo y, en lo que respecta a sus contenidos, apegados por completo a los hechos sometidos a juicio (Ritoré, 2005, p. 131).

\section{La innovación de Hrotsvita}

Dos principales derroteros se muestran en esta autora, el drama terenciano y la literatura hagiográfica. Si bien,

Drama was prohibited and repeatedly castigates by the Church for its mimetic power, although Terence was read in schools because of his eloquence; sacred biography, conversely, was advocated and promoted by the Church as a powerful tool of teaching and preaching because or its mimetic potential, since the life of the saint functioned as a mimetic paradigm; aesthetically, however, hagiographic texts ranged from the marginally literate and clumsily simplistic examples of the early Middle Agest to the ornate and eloquent compilations of the eleventh and twelfth centuries (Hrotswitha of Gandersheim, 2000, p. 112).

Respecto de Terencio, aunque se habría separado de la composición en verso, recurrió a la prosa rimada, una solución intermedia entre el verso y la prosa.

De él ha de haber tomado su exquisito gusto por la pulcritud del latín clásico, al que tiende por excelencia. Para Bonfante, este rasgo estaría fundado en lo siguiente:

Some of her insistence on that influence might have been due to her desire to have her work recognized as classically inspired by medieval critics and scholars -Terence was one of the four most important Classical authors of late antiquity and the Middle Ages, along with Vergil, Cicero and Sallust (Hrotswitha of Gandersheim, 2013, p. x).

Sin embargo, es innegable que: "She wished to use the Terentian form because he was read and enjoyed, and she wished to provide a substitute for that reading and enjoying" (Hrotswitha of Gandersheim, 2000, p. 116).

En igual sentido, la cuidadosa caracterización de sus personajes es de eminente raigambre terenciana.

En relación con la hagiografía, Hrotsvita se separa de las acta y sus rasgos narrativos. Se decanta, en cambio, por el drama: 
Hrotswitha's decision to express themes of hagiography in dramatic form in motivated by a moral imperative to rewrite Terence, to use the effectiveness of his form and the excitement of events as presented in dialogue on the side of the Christian ethic (Hrotswitha of Gandersheim, 2013, p. xviii).

Complementa esta elección con la incorporación de diversos subgéneros, ya pertenecientes a los sermones, ya a la liturgia cristiana, ya a su doxología. A esta última pertenece la expresión cui est honor et gloria in saecula. ${ }^{3}$

En síntesis, hay un cambio en el género de expresión y comunicación, cuyo uso no es canónico. Este, a su vez, se ve enriquecido con un proteico sincretismo de géneros.

\section{La influencia de las acta}

Las acta son unas de las fuentes en las que bebe esta autora, en particular respecto del martirio de las santa Ágape, Quionia e Irene, cuyos nombres significan, respectivamente, amor, pureza y paz.

El martirio de estas jóvenes también ha de haber influido en otras obras de esta monja benedictina. Así, por ejemplo, el contexto de los burdeles también se encuentra en Abraham y Paphnutius. Por su parte, en Sapientia se dramatiza también un proceso judicial de tres mujeres, en este caso, personificadas en sendas virtudes, Fides, Spes y Karitas; ${ }^{4}$ donde el juicio tendrá lugar no ante Diocleciano, sino ante Adriano.

\section{Variaciones argumentales}

De acuerdo con las acta, Casandro, un soldado, denuncia que Agatón, Ágape, Quionia, Irene, Casia, Felipa y Eutiquia se niega a comer de los sacrificios de los dioses. Esto da lugar al proceso. Luego de ser interrogada, Ágape y Quionia son condenadas a la hoguera.

\footnotetext{
${ }^{3}$ Traducción propia: "para quien es el honor y la gloria por todos los siglos".

${ }^{4}$ Traducción propia: "Fe, Esperanza y Caridad".
} 
Irene, en cambio, es conservada viva. Pasado un tiempo, Dulcicio la vuelve a llamar y le recrimina el haber conservado los libros sagrados. Ella persevera y se niega a sacrificar a los dioses. Así las cosas, es condenada a ser llevada desnuda a un lupanar, pero allí nadie se atreve a tocarla. Por eso, Dulcicio decreta que sea quemada viva. Así se hace y es llevada donde murieron sus hermanas en la fe. Irene misma se arroja a la hoguera y muere en las calendas de abril.

En la composición de Hrotsvita, en cambio, únicamente figuran las santas Ágape, Quionia e Irene, quienes tienen tres comparecencias: una primera ante el emperador Diocecliano, una segunda ante Dulcicio y una última ante Sisinio. Superada la estancia ante el emperador, son remitidas al gobernador Dulcicio quien, llevado por su lujuria, pretende abusar de ellas; empero, algo fantástico ocurre, una especie de "milagro" tiene lugar: Dulcicio sufre una confusión mental que lo hace regodearse con las ollas de la cocina creyendo que son las jóvenes. Ellas, en cambio, se encuentran a distancia a salvo y, atentas y burlonas, contemplan la escena. Dulcicio ordena que las tres sean desnudadas públicamente, pero no pudieron quitarles los vestidos. Diocleciano se entera de lo ocurrido

y decreta que ellas sean llevadas ante Sisinio. Seguidamente, Ágape y Quionia son condenadas a la hoguera, pero sus espíritus vuelan a Dios y sus cuerpos permanecen incorruptos. Por último, Irene es condenada a ser quemada, pero unos personajes misteriosos la toman y la llevan a un monte, donde uno de los soldados de Dulcicio la hiere con una flecha y ella muere.

\section{Dulcitius como obra cómica}

El adjetivo trágico, tragikós, que existe ya en el griego clásico, designa, como es la regla en todos los adjetivos formados en -ikós, no otra cosa sino la pertenencia a la tragedia, o bien expresa que una cosa está hecha al modo de la tragedia. Así, en la Poética de Aristóteles (c.13, 1453a, 30), Eurípides es el poeta "más trágico", porque escribe tragedias que se corresponden mejor con las ideas del filósofo, sobre todo en relación con el objetivo de la tragedia de provocar temor y compasión (Zimmermann, 2012, p. 145). 
Ahora bien, ¿es el Dulcitius una tragedia? En realidad, el Dulcitius es considerado un drama cómico, valoración en la que se acusa la presencia de conceptos aristotélicos, ya que:

Según Aristóteles, el objetivo de la tragedia es el de producir una "purificación” (catarsis) en el sentido médico psicológico (c.6, 1949b, 2428), y el origen del concepto y de las ideas hay que buscarlo en el culto a Dioniso. El público se ve "purificado" y liberado de las emociones de temor y compasión que experimenta al contemplar la acción dramática (Zimmermann, 2012, p. 140).

En efecto, tales emociones no están presentes en la obra. Por el contrario, la valentía que manifiestan las heroínas y la glorificación a que están llamadas son incompatibles con tales emociones.

Además, ha de recordarse que:

Solo queda como héroe trágico ideal una persona entre los extremos, a quien golpea la desgracia a causa de un error suyo, de un comportamiento equivocado, tal como sucede de manera ideal en el caso de Edipo. El sufrimiento inmerecido que cae sobre el héroe trágico despierta, por un lado, la compasión y, por otro, su carácter "híbrido" posibilita que el espectador se identifique con él (c.13, 1452b, 30ss) (Zimmermann, 2012, p. 140).

En esta obra, si bien la persecución de que son objeto las heroínas se propone como injusta, no ha habido ningún error culpable de su parte: ellas son conscientes de su decisión, la cual ha sido voluntaria, y asumen con honor y fortaleza todas sus consecuencias. La empatía que se establece se construye sobre presupuestos distintos, ya que parte del paralelismo de status (cristiano) entre el lector/auditorio y los personajes, y llama no tanto a compasión, cuanto a imitación.

Dulcitius, en cuanto drama, tiene un carácter doble: posee rasgos de tragedia junto a elementos cómicos, tal y como pudo ocurrir en la antigüedad griega, lo cual destaca Máximo Brioso: 
Pero a la vez esa división en dos formas dramáticas básicas [se refiere a la tragedia y la comedia] ofrece unas posibilidades extraordinarias, que permiten al mismo tiempo profundizar y enriquecer cada una de ellas y, en lo posible y sin su desvirtuación, provocar trasvases de la una en la otra, como ocurre sobre todo con las paratragedias cómicas o, en un ejemplo particular y extremo, con la aparición como personajes de una comedia [Ranas] de dos afamados autores trágicos. No es, pues, sólo la oposición lo que rige la labor de los autores, por ejemplo, en cuanto a la elección del argumento [el mito, rara vez la historia, para la tragedia; la invención libre para la comedia] o la clase de final [patético o trascendente frente al feliz y festivo], o incluso la estructura de la obra; es también la vecindad la que sugiere nuevas posibilidades (Brioso, 2005, p. 177).

En la obra objeto del presente estudio, se aprecia que su objeto es el propio de la tragedia, no solo en cuanto a los personajes, como apunta Diomedes, sino por cuanto su argumento parte de un mito con rasgos históricos.

Por otro lado, la unidad y coherencia de la narración apuntan a una mayor influencia de la comedia romana, particularmente la terenciana, así como de la Nea, comedia de origen helenístico que, hacia los siglos IV y III a. C., marcó un renacer de este género en la Antigüedad.

En el plano lingüístico, también se aprecian las particularidades de esta obra, ya que lo culto predomina frente a lo popular, características que, con el perdón de caer en una simplificación excesiva, se asocian a la tragedia, por un lado, y a la comedia, por otro, respectivamente. Empero, el ánimo festivo se encuentra atenuado.

El final feliz es de orden conceptual, se encuentra en la visión beatífica que alcanzarán las heroínas. No obstante, tal desenlace no tiene lugar en la escena.

\section{La tradición argumentativa de las persecuciones}

Para comprender el contexto en el que tienen lugar las persecuciones, es menester tener presente que en aquella época: 
La ciudad, no la fe ni el sentimiento individual, imponía la norma en la relación del hombre con la divinidad. Para Roma, Cicerón nos ha conservado un precioso texto legal antiguo: Separatim nemo habessit deos; neve novos, neve advenas, nisi publice adscritos, privatim colunto (Del leg. II, 8). Nadie puede separarse de la ciudad en el culto a los dioses, como no puede nadie infringir sus leyes o negarle su servicio sin dejar, ipso facto, de ser ciudadano y caer bajo su justa vindicta (Ruiz, 1968, p. 78).

En efecto,

No hay que perder de vista - dice un buen juez en la materia-que en las edades antiguas era el culto el que formaba el lazo de unión de toda sociedad. A la manera que un altar doméstico congregaba en torno a sí a los miembros de una familia, así la ciudad (y por ciudad hay que entender el Estado) era la reunión de los que tenían los mismos dioses protectores y cumplían el acto religioso en el mismo altar (de Coulanges, citado por Ruiz, 1968, p. 77).

He aquí el quid de la imposibilidad de entendimiento en los procesos seguidos contra los cristianos: para las autoridades romanas era incomprensible que los cristianos se negaran a sacrificar a los dioses y que, en cambio, prefirieran morir. Para quienes ejercían el poder, la relación personal con Dios, la fe, no tenía ninguna relevancia; en cambio, el vínculo con la comunidad política era lo fundamental. Para aquellos, el verdadero peligro era la muerte física, para los otros, la muerte eterna, la muerte del alma.

Estos dos sistemas axiológicos permiten comprender que tanto para la autoridad romana como para los mártires, los umbrales de persuasión para la tesis de sus oponentes eran muy elevados, situación agravada por el escaso o nulo valor que se atribuía a sus argumentos.

Estos umbrales marcan, para una cultura o un sujeto, la valoración que debe recibir una argumentación para que se considere persuasiva. De esta manera, respecto de una persona que agrade al interlocutor, usualmente el umbral suele ser más bajo que respecto de alguien que se ve afectado por un prejuicio. 
El corolario a este proceso de incomprensión es obvio: no solo no se comprendía a la contraparte, sino que parecía una locura su actitud. Esto está ilustrado en los adjetivos empleados por los interlocutores en los distintos procesos. Por ejemplo, Diocleciano califica de fatuitas ${ }^{5}$ inutilem christianae novitatem superstitionis $;{ }^{6}$ además, tilda de insanit $^{7}$ a las acusadas; e, incluso, llega a afirmar ista dementius bachatur. ${ }^{8}$ A tal imputación, una de las hermanas responde: “Chionia. mea germana non insanit,| sed tui stultitiam iuste reprehendit". 9

Las acusadas también descalifican la tesis de los acusadores, así Irene las denomina como inhonestas turpior, quae turpitudo maior. ${ }^{10}$ Para los acusadores, la amenaza era la muerte física, para las acusadas el verdadero peligro era la muerte eterna, la muerte del alma.

El poder romano, maestro por excelencia de la retórica del miedo, dirige la atención de las procesadas ante la amenaza explícita contra sus bienes físicos y morales: ya su vida, ya la de sus amigas, ya su castidad...

Hrotsvita pone de manifiesto el menosprecio a tales amenazas en boca de los soldados del gobernador:

Dulcitius. quid, si terream suppliciis?

Milites. parvi pendunt. ${ }^{11}$

\footnotetext{
5 Traducción propia del original: "estupidez”.

${ }^{6}$ Traducción propia del original: "inútil novedad de la superstición de los cristianos".

${ }^{7}$ Traducción propia del original: "está loca”.

${ }^{8}$ Traducción propia del original: "esta delira demencialmente como bacante”.

9 Traducción propia del original: "Mi hermana no está loca, al contrario, reprende con justicia tu estupidez".

${ }^{10}$ Traducción propia del original: "Vergüenza más deshonrosa, la mayor deshonra".

${ }^{11}$ Traducción propia del original: "Dulcicio. ¿Y si las atemorizo con la amenaza de suplicios terribles?
}

Soldados. Los estiman en muy poca cosa". 
En este aspecto llama la atención que en "tratándose de los cristianos, ni la lógica ni la ley tenían vigencia” (Ruiz, 1968, p. 117).

Ciertamente, la tortura en la Antigüedad era empleada como medio para obtener la confesión del delito. Sin embargo, los cristianos confesaban su fe sin necesidad de ser torturados. Este recurso, en cambio, se dirigía, no a obtener la confesión, sino la retractación. Para la mentalidad de un pagano, esto podía ser considerado, incluso, un acto de piedad, ya que iba irigido a que los acusados salvaran sus vidas (Ruiz, 1968, p. 116).

La respuesta no se hace esperar: en consonancia con la tradición teológica y doxológica, responden con el menosprecio a las amenazas. Dos variables introducidas y ampliamente desarrolladas por Hrotsvita son las réplicas ágiles de las acusadas y el empleo de la risa.

Desde el inicio de la obra esto es manifiesto: en la primera escena, Diocleciano se muestra interesado por el destino matrimonial de las acusadas. Sin embargo, Ágape responde con ironía: esto securus curarum. ${ }^{12}$ A partir de este momento, inicia un intercambio de réplica que se apropian, acusador y acusadas, del léxico de su oponente, tal y como muestra el siguiente pasaje:

Hirena. conquiniscant idolis,| qui velint incurrere iram celsitonantis!| ego quidem caput regali unguento delibutum non dehonestabo| pedibus simulachrorum submittendo.|

Diocletianus. cultura deorum non adducit inhonestatem,| sed praecipuum honorem.|

Hirena. et quae inhonestas turpior,| quae turpitudo maior,| quam ut servus| veneretur ut dominus?|

Diocletianus. non suadeo tibi venerari servos,| sed dominos principumque deos.|

Hirena. nonne is est cuiusvis servus,| qui ab artifice pretio comparatur ut empticius? $\left.\right|^{13}$

\footnotetext{
12 Traducción propia del original: "eres libre de todo cuidado".

13 Traducción propia del original: "Hirena. ¡Que inclinen sus cabezas ante los ídolos, quienes quieran despertar la ira del que hace tronar los cielos! Yo no deshonraré mi cabeza, ungida con un ungüento real, inclinándola ante los pies de los ídolos. Diocleciano. El culto a los dioses no conduce a la vergüenza, sino al mayor honor. Hirena. Pero, dígame, ¿cuál vergüenza es más deshonrosa que esta, la mayor deshonra: el que a
} 
Incluso, las acusadas dan un giro a la retórica del miedo al invertir los términos de la relación:

Agapes. temere calumpniaris| statum dei omnipotentis.| periculum -

Diocletianus. cuius?

Agapes. tui reique publicae, quam gubernas. ${ }^{14}$

\section{Conclusiones}

El examen precedente ha puesto de relieve la forma cómo influyeron en Hrotsvita tanto las acta como Terencio. Destaca sobremanera la libertad con que esta autora se distanció inteligentemente de las fuentes de las que ha bebido al mezclar distintos géneros y tradiciones textuales, al separarse de las definiciones canónicas para los subgéneros dramáticos comprometidos y desarrollar las procesos argumentativos de sus personajes.

Ciertamente, en el caso de Hrotsvita se está ante una autora que ha marcado un hito en el curso de la literatura latina occidental que merece estudios profundos para ampliar nuestro conocimiento de su obra.

\section{Referencias bibliográficas}

Bershin, W. (1985). Passio und Theater. Zur dramatischen Struktur einiger Vorlagen Hrotsvit von Gandersheim. En Herman Braet, Johan Nowé y Gilbert Tournoy (Eds.), The Theater in the Middel Ages (pp. 1-11). Bélgica: Leuven University Press.

\footnotetext{
un esclavo se le venere como a un señor? Diocleciano. No te aconsejo venerar a los esclavos, sino a los señores y principalmente a los dioses. Hirena. Pero, ¿no es siervo de un cualquiera quien, a un precio artificioso, es comprado como mercancía?

14 Traducción propia del original: “Agapes. Acusas injustamente que temamos la condición del Dios Todopoderoso. Esto es peligroso. Diocleciano. ¿Para quién? Agapes. Para ti y para la república que gobiernas".
} 
Brioso, M. (2005). Sobre las convenciones escénicas de la tragedia y la comedia clásicas. En Máximo Brioso Sánchez y Antonio Villarrubia Medina (Eds.), Aspectos del teatro griego antiguo (pp. 173-252). Sevilla: Secretariado de publicaciones de la Universidad de Sevilla.

Hroswitha of Gandersheim. (2000). Hroswit of Gandersheim: a Florileium of her Works. Tranlated with introduction, interpretative essay and notes, Katharina Wilson. Reprinted. Cambridge: D. S. Brewer.

Hroswitha of Gandersheim. (2013). The Hroswitha of Gandersheim. Bilingual Edition. Tranlated by Larissa Bonfante. Edited by Robert Chipok (1. ${ }^{\text {st }}$ edition). Illinois, EE. UU.: Bolchazy-Carducci Publishers, Inc.

Prampolini, S. (1955). Historia Universal de la Literatura, III (2. ${ }^{\text {a }}$ edición). Buenos Aires: UTEHA.

Ritoré, J. (2005). Tragedia y retórica. En Máximo Brioso Sánchez y Antonio Villarrubia Medina (Eds.), Aspectos del teatro griego antiguo (pp. 121-142). Sevilla: Secretariado de publicaciones de la Universidad de Sevilla.

Ruiz, D. (1968). Actas de los mártires. Texto bilingüe. Introducción, notas y versiónespañola por Daniel Ruiz Bueno (2. edición). Madrid: Editorial Católica.

Zimmermann, B. (2012). Europa y la tragedia griega. De la representación ritual al teatro actual. Traducción de José Antonio Padilla Villate. Revisión técnica de Carlos García Gual. Madrid: Siglo XXI de España Editores.

\section{(c) $(7) \odot$}

Esta obra está bajo una licencia de Creative Commons Reconocimiento-NoComercial$\underline{\text { SinObraDerivada 4.0 Internacional }}$ 